\section{An Efficiently-folding Purely-symmetric de novo Designed Protein}

\section{Michael Blaber}

Biomedical Sciences, College of Medicine, Florida State University, USA

*Corresponding author: Michael Blaber, Biomedical Sciences, College of Medicine, Florida State University, USA, Tel: 850-644-3361; E-mail: michael.blaber@med.fsu.edu

Rec date: Mar 27, 2015; Acc date: Mar 30, 2015; Pub date: Mar 31, 2015

Copyright: $\odot 2015$ Blaber M, et al. This is an open-access article distributed under the terms of the Creative Commons Attribution License, which permits unrestricted use, distribution, and reproduction in any medium, provided the original author and source are credited.

\section{Introduction}

Many globular protein folds exhibit some form of rotational symmetry - the most common example being the TIM barrel (having 8 -fold rotational symmetry of a repeating beta-strand/turn/alphahelix/turn motif). This type of common symmetry in proteins was apparent from the earliest days of X-ray structure studies, leading to the hypothesis that gene duplication and fusion was the underlying evolutionary mechanism. However, while such symmetry at the $3^{\circ}$ structure level is apparent, any $1^{\circ}$-structure symmetry when comparing repeating structural motifs is often largely absent. Such sequence analyses, along with theoretical considerations of folding frustration for exact repeating motifs, as well as natively-unstructured properties for peptides having reduced sequence complexity (as occurs with exact repeating motifs), resulted in a paradigm that proteins designed with exact symmetry are unlikely to be efficiently folding. Given that exact symmetry can substantially reduce the combinatorial explosion problem inherent to protein design, turning such problems from impossible to computationally tractable, the demonstration of efficient folding for purely symmetric de novo designed proteins took on considerable interest. The attached image is of the Symfoil-4T protein - a purely-symmetric de novo designed protein based upon the common beta-trefoil architecture and reported by Blaber and coworkers. The Symfoil-4T protein is a hyperthermophile, two-state efficiently folding protein, and its successful design opened the door to symmetric protein design principles. Further successful symmetric protein design by other investigators followed Symfoil-4T, including the "Threefoil" protein designed by Meiering and coworkers, and the "Pizza" protein designed by Tame and coworkers [1-3] (Figure 1).

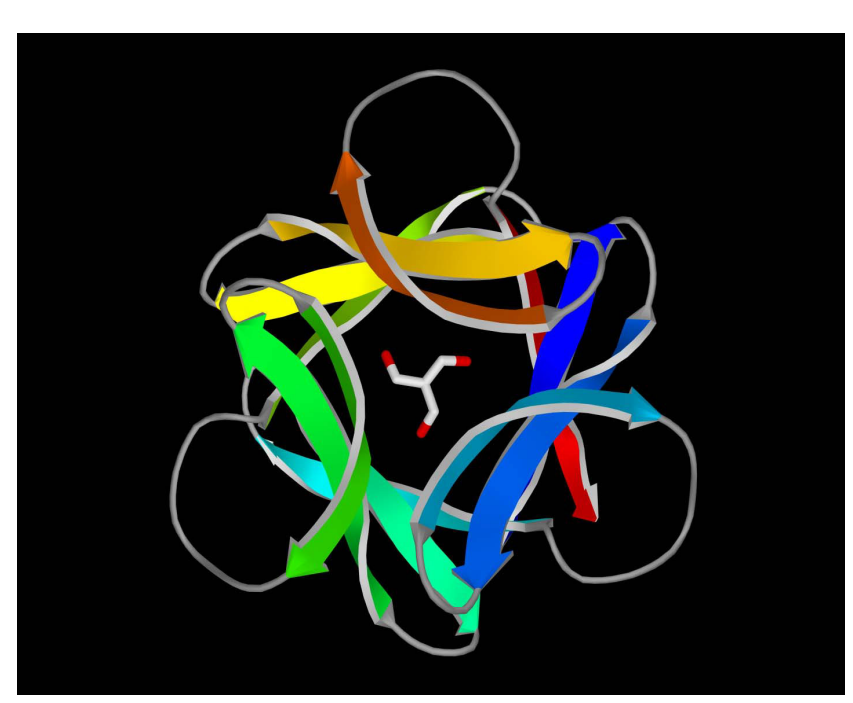

Figure 1: X-ray crystallography structure of protein.

\section{References}

1. Lee J, Blaber M (2011) Experimental support for the evolution of symmetric protein architecture from a simple peptide motif. Proceedings of the National Academy of Sciences of the United States of America 108: 126-130.

2. Broom A, Doxey AC, Lobsanov YD, Berthin LG, Rose DR, et al. (2012) Modular evolution and the origins of symmetry: reconstruction of a threefold symmetric globular protein. Structure 20: 161-171.

3. Voet ARD, Noguchi H, Addy C, Simoncini D, Terada D, et al. (2014) Computational design of a selfassembling symmetrical -propeller protein. Proceedings of the National Academy of Sciences of the United States of America 111: 15102-15107 